\title{
Main Factors Affecting Mechanical Characteristics of Silicon Carbide Sludge-Based Geopolymer Revealed by Experimental Design and Associated Statistical Analysis
}

Lin Kae-Long ( $\nabla$ kllin@niu.edu.tw )

National I-Lan University https://orcid.org/0000-0002-8549-5721

Kang-Wei Lo

National Taipei University of Technology

Ya-Wen Lin

National Taipei University of Technology

Ta-Wui Cheng

National Taipei University of Technology

\section{Research}

Keywords: Design of experiment, Silicon carbide sludge, Factor parameter, Multivariate adaptive regression splines model, Regression curve

Posted Date: June 9th, 2021

DOI: https://doi.org/10.21203/rs.3.rs-539718/v1

License: (9) This work is licensed under a Creative Commons Attribution 4.0 International License.

Read Full License 


\section{Abstract}

In recent years, many researches have been analyzed on the subject of geopolymer materials. As far as we know, the design of experiments (DOE) methods had not been used for the analysis of geopolymer containing silicon carbide sludge (SCS) waste and metakaolin components. This study was used to quantify the effects the interaction between the constituent factors and macroscopic / microstructure properties of SCS-based geopolymers (SCSGPS), by the DOE methods. Compares the correlation between the factor parameters and physical properties, which were analyzed the microstructure analysis of SCSGPs. The results of statistical analysis showed that the influencing factors of compressive strength of SCSGPs were mainly $\mathrm{Na}$ / Si mole ratio (NSR), $\mathrm{Na}$ / Al mole ratio (NAR), followed by dissolution rate of Al (DRA). In the regression curve analysis results, when the SCS replacement levels of $20 \%$, the coefficient of b was the most influential, because the synergistic effect between metakaolin (MK) and SCS. In this study, the multivariate adaptive regression splines model provided a valid reference for the application of and future improvements in SCSGPS.

\section{Introduction}

In recent years, the Light-Emitting Diode (LED) industry was widespread used in indicators and display devices of information [1], communication and consumer electronic products with the economy and industry were flourishing in Taiwan [2]. A large amount of silicon carbide (SiC) sludge waste will be generated during the process of cutting silicon ingot into wafer. Its cutting loss exceeds 50\% [3]; according to the research statistics of Lan et al., the global silicon wafer manufacturing industry spent about 400,000 tons of silicon ingots to produce silicon wafers in 2018 [4]. The process of cutting into wafers produced about 200,000 tons of silicon carbide sludge (SCS). Because the SiC sludge contains alumina $\left(\mathrm{Al}_{2} \mathrm{O}_{3}\right)$ and $\mathrm{SiC}$, it is the main component of natural kaolin. If it can be recycled, which can not only reduce production costs, but also reduce environmental pollution, and in accordance with the environmental protection administration goal of zero waste and zero landfill resources.

Davidovits began to develop a material called "Geopolymer" in the 1970s [5]. Geopolymer is an inorganic polymer synthesized by aluminosilicate under strong alkali conditions [6]. Geopolymer have the characteristics of high mechanical strength, thermal stability, low shrinkage, acid resistance and low carbon dioxide emissions [7-10]. Therefore, it has great potential for construction materials application. In addition, the geopolymer also has favorable fire-resistance and non-smoke characteristics [11, 12], hence this feature can be used to make environmentally friendly fireproof board. In the geopolymerization, the chemical reaction of an aluminosilicate with silicates under highly alkaline conditions [13]. By the sodium hydroxide $(\mathrm{NaOH})$ and sodium metasilicate solutions, the rapidly dissolving aluminosilicate released $\left[\mathrm{SiO}_{4}\right]^{-}$and $\left[\mathrm{AlO}_{4}\right]^{-}$into the liquid, and each tetrahedron shared its oxygen atoms with the precursor substance of the polymer $[6,14]$ to generate an amorphous threedimensional network structure. Due to charge balance and catalytic performance, the presence of $\mathrm{Na}^{+}$ was important. Therefore, the main results that affect the geopolymerization include aluminosilicate raw 
materials, curing conditions, types of alkali activators, combinations and concentrations of activators, and the ratio of alkali activators to binder. They determine the properties of geopolymer. So far, many mixture design parameters have been determined, whether chemical or physical, will affect the compressive strength of geopolymer. For example, the ratio of $\mathrm{SiO}_{2} / \mathrm{Al}_{2} \mathrm{O}_{3}$ and $\mathrm{Na}_{2} \mathrm{O} / \mathrm{Al}_{2} \mathrm{O}_{3}$ of raw materials, the amorphous material, $\mathrm{CaO}$ content and workability of raw materials [15-17]. On the other hand, Diaz-Loya et al [18] analyzed that influenced the final mechanical strength and the water / solid (W / S) ratio has a positive effect for the geopolymer mixture. In addition, Rattanasak and Chindaprasirt [19] reported that the rapidly dissolving fly ash released aluminosilicate by the higher concentration of $\mathrm{NaOH}$ solution, which promoted the early geopolymerization. Bakiri et al. [20] and Songpiriyakij et al. [21] showed that the ratio of sodium metasilicate / $\mathrm{NaOH}$ was a mainly parameter for strength development, and other paper [18, 22-27] indicted that curing condition (e.g., temperature and time) also had a positive effect on the macroscopic / microstructure of geopolymer. The relationship between key bonds and structural types and the macroscopic properties of inorganic polymers has not been clearly determined, and also need to explain the relationship between polymerization and macroscopic / microstructure properties. Many factors could possibly influence the macroscopic / microstructure properties of geopolymers. However, through a well-designed experimental process, the influence of various parameters on the geopolymer can be fully explored, well-known design of experiments (DOE) methods can be used for this purpose.

According to the research statistics of Lan et al., the global silicon wafer manufacturing industry spent about 400,000 tons of silicon ingots to produce silicon wafers in 2018 [28]. The process of cutting into wafers produced about 200,000 tons of SiC sludge (SCS). Because the SiC sludge contains alumina $\left(\mathrm{Al}_{2} \mathrm{O}_{3}\right)$ and $\mathrm{SiC}$, it is the main component of natural kaolin. If it can be recycled, which can not only reduce production costs, but also reduce environmental pollution, and in accordance with the environmental protection administration goal of zero waste and zero landfill resources. The goals of the Waste Electrical and Electronic Equipment (WEEE) directive are to prevent the inappropriate disposal of electrical and electronic equipment waste, to reuse and recycle waste, and to reduce e-waste deposition in landfills. This directive highlights can indicate the need to address the SCS problem. This study uses experimental design to propose design parameters for SCS-based geopolymer (SCSGP). In the subsequent statistical analysis, it is regarded as an independent variable factor to study the influence of component factors on the development of mechanical properties, and consider the interaction between different components and study the effects of molecular composition and related interactions. In this study, through macroscopic / microstructure analysis such as workability, porosity, Mercury intrusion porosimetry (MIP) and Scanning Electron Microscope (SEM), and establish its regression curve to explore the relationship between mechanical properties and microstructure characteristics of SCSGP. It is expected to provide a scientific basis for the further development and standardization of the SCS mixture design process to facilitate the application of geopolymers.

\section{Materials And Methods}




\subsection{Materials and sample preparation}

The SCS-based geopolymers (SCSGPS) consisted of kaolin, SCS and an alkaline solution in this study. Metakaolin (MK) was generated from the kaolin by calcination at $650^{\circ} \mathrm{C}$ in air for $3 \mathrm{~h}$. After crushing in a ball mill, the fineness of the SCS powder was controlled to $300-400 \mathrm{~m}^{2} / \mathrm{kg}$, and the properties were shown in Table 2. The SCS consisted of $75.40 \% \mathrm{SiO}_{2}, 0.80 \% \mathrm{Al}_{2} \mathrm{O}_{3}$ and $23.00 \% \mathrm{SiC}$; and $\mathrm{MK}$ consisted of $51.80 \% \mathrm{SiO}_{2}, 43.00 \% \mathrm{Al}_{2} \mathrm{O}_{3}$ and $1.30 \% \mathrm{Fe}_{2} \mathrm{O}_{3}$. Reagent grade $\mathrm{NaOH}$ was added to deionized water and allowed to release heat for $24 \mathrm{~h}$. The $\mathrm{S} / \mathrm{N}$ ratio of the sodium metasilicate solution was 3.1, and the two solutions were subsequently mixed under stirring for $10 \mathrm{~min}$ at the required $\mathrm{S} / \mathrm{N}$ ratio (Table $1 \mathrm{~b}$ ). After the heat release process, the alkaline solution was added to the MK and stirred at a low speed for 2 min. Then, it was stirred at a medium speed for $5 \mathrm{~min}$, and the samples were subsequently cast by pouring the geopolymer paste into cubic plastic molds of $25.4 \times 25.4 \times 25.4 \mathrm{~mm}$. Using a shaker, air was removed from the sample, which was subsequently cured at a constant temperature of $30 \pm 2^{\circ} \mathrm{C}$ and constant humidity for 1 day. The sample was removed from the cubic plastic mold and then further cured under the same conditions for 28 days.

\subsection{Experimental design}

In order to determine the influence of various constituent factors of SCS in the preparation of curing geopolymers and the related interaction between these components on the subsequent mechanical properties. This research is based on the four main control factors were selected: $\mathrm{SiO}_{2}$ to $\mathrm{Na}_{2} \mathrm{O}$ ratio ( $\mathrm{S} /$ $\mathrm{N}$ ), solid to liquid ratio (S / L), metakaolin (MK) and SCS, and sample preparation, and the mixed combination was designed into 35 groups. Table 1 lists the design mixing ratios related to the four factors. Multivariate regression analysis and analysis of variance (ANOVA) were employed to find out the factors with significant influence of different additives and clarify the interaction between the same factors. Finally, the multiple regression model is established according to the experimental results.

\subsection{Test items and methods}

In this study, the analysis of geopolymers were classified according to factor parameters, physical properties and microstructure. Factor parameters include $\mathrm{Si}, \mathrm{Al}$ and $\mathrm{Na}$ ion concentrations. By using the same content of MK, SCS and alkaline solution as in the experimental design method, the concentration of $\mathrm{Si}, \mathrm{Al}$ and $\mathrm{Na}$ ions was measured in the separation experiment. First, mix the alkaline solution with $\mathrm{MK}$ and SCS for $60 \mathrm{~min}$. Subsequently, 3.8 L of water was added to the mixture and the suspension was stirred for $30 \mathrm{~s}$. The slurry was further diluted to avoid precipitation. After filtration, the dissolved $\mathrm{Si}, \mathrm{Al}$, and $\mathrm{Na}$ ion concentrations were analyzed by atomic absorption spectroscopy (AAS) [29]. Physical properties include the compressive strength test (ASTM C109), where a square sample of $2.54 \times 2.54 \times$ $2.54 \mathrm{~cm}^{3}$ is used to determine the compressive strength of the geopolymer. Table 1 shows the mixing ratio of geopolymers. Use three samples for mechanical testing, and the test results were the average 
value of the samples. Univariate and multivariate regression analyses, including ANOVA, were executed using the SPSS Statistics 17.0 software, which were employed to find out the factors with significant influence of different additives and clarify the interaction between the same factors. According to the experimental results, establish its multiple regression model. By the macroscopic / microstructure analysis of workability, porosity, MIP and SEM, and the establishment of its regression curve, the relationship between the mechanical properties and microstructure characteristics of the SCSGP was discussed. MIP evaluated cumulative pore volume using an Autopore IV 9500 porosimeter. The geopolymer sample was crushed to produce $5-15 \mathrm{~mm}$ pieces and dried at $105^{\circ} \mathrm{C}$ for the MIP test. SEM images were obtained using a Hitachi S-3500 N to show the geopolymer microstructure. It is expected to provide a scientific basis for the further development and standardization of the SCS mixture design process to facilitate the application of geopolymers.

\section{Results}

\subsection{Factor parameters and physical properties test results}

Table 3 shows the compressive strength results of each mixed ratio of SCSGP. The compressive strengths for the mix proportions were $3.52-66.08 \mathrm{MPa}$ in the design range. This study applied multivariate statistical analysis to determine the key factors affecting the mechanical parameters of SCSGPs. By using multiple regression analysis, relevant quantitative relationships can be established. It was important to discriminate between a linear and nonlinear relationship between the independent and dependent variables before the multivariate statistical analysis. This study also examined the collinearity of the independent variables, and one factor was selected based on the collinearity to avoid having to use the significant relationship of the independent variable. Then, based on the residual sum of squares (SSR) obtained from statistical analysis, the t independent test (95\%) was used to select the main independent $t$ variable, and the other factors were increased or decreased to further test the selected variable to identify significant relationships with the independent variable and interactions between the factors. Finally, the crucial factor relationship with the macroscopic properties of the SCSGP was analyzed, and multiple regression equation were established based on the experimental results.

\subsection{Original material analysis}

Fig. 1 shows the results of the statistical analysis of the normalization between the raw materials and compressive strength in the SCSGPs. The correlation between all raw materials (i.e., MK, SCS, $\mathrm{Na}_{2} \mathrm{SiO}_{3}$ and $\mathrm{NaOH}$ ) and compressive strength were best described by an exponential relationship, and all the variance inflation factor (VIF) were less than 10. Table 4 listed the results of the multiple regression analysis of the compressive strength and interaction between the raw materials. The results of the t-tests showed that MK was the most significant factor in terms of the compressive strength, followed by $\mathrm{Na}_{2} \mathrm{SiO}_{3}$. Among the interaction factors, MK has the strongest correlation with SCS and SCS with $\mathrm{Na}_{2} \mathrm{SiO}_{3}$. 


\subsection{Dimensionless ratio analysis}

After separating the raw materials, multiple regression analysis was performed again to determine the relationship between the compressive strength of the SCSGPS and the dimensionless ratios (i.e., SN, SL, $\mathrm{OH}^{-}$and $\mathrm{OW}$ ), as shown in Table 5. According to the result of t-test (95\%), OW has the greatest influence, followed by SL, and SN has less influence on the all compressive strength (Table 5). Therefore, we inferred that the factors of $\mathrm{OH}^{-}, \mathrm{SiO}_{2}, \mathrm{Na}_{2} \mathrm{O}$ and $\mathrm{H}_{2} \mathrm{O}$ were the significantly affect by the compressive strength of SCSGPs. At the highly alkaline conditions, when the rapidly dissolving aluminosilicate released $\left[\mathrm{SiO}_{4}\right]^{-}$and $\left[\mathrm{AlO}_{4}\right]^{-}$ions in the solution, the tetrahedron shares oxygen atoms with the polymer precursor [30,31], thereby forming the polymeric $\mathrm{Si}-\mathrm{O}-\mathrm{Al}-\mathrm{O}$ bonds on the geopolymerization $[14,31]$. However, the VIF results showed that $\mathrm{OH}^{-}(\mathrm{mol})$ and $\mathrm{Na}_{2} \mathrm{O}(\mathrm{mol})$ exhibited high collinearity, when $\mathrm{OH}^{-}$ was treated as a reaction concentration, not the alkalinity. Therefore, $\mathrm{OH}^{-}(\mathrm{mol})$ and subsequently the Na / Si mole ratio (NSR), Na / Al mole ratio (NAR), DRS, and dissolution rate of Al (DRA) were selected to calculate the molar concentrations of the factors in the reaction process for the multiple regression analysis in order to determine their influences on the compressive strength of the SCSGPs.

Table 6 lists the multiple regression results of relationship between NSR, NAR, DRS, DRA, $\mathrm{OH}^{-}$and the compressive strength, which also determined the interactions of these important factors. It's worth noting that the results of the multiple regression analysis found interactions between the NSR and DRA and between the NAR and DRA.

NSR and NAR were the most significant factors, followed by DRA, the following regression equation had highly representative $\left(r^{2}=0.869\right)$, and meaning these three coefficients were sufficient to describe the compressive strength of SCSGPS.

\section{Compressive Strenggth $(\mathrm{MPa})=0.550(\mathrm{NSR})-0.495($ NAR $)-$

$$
0.383(D R A)-0.211(N S R)(D R A)
$$

Fig. 2 illustrates the compressive strength and the first three important factors, i.e., the relationship between NSR and DRA and the relationship between NAR and DRA, through the multivariate adaptive regression splines. In the design range in this study, the highest compressive strength of the SCSGP was $66.08 \mathrm{MPa}$, which was obtained through NSR of 0.15 , NAR of 0.22 , and DRA of $58.24(\%)$.

\section{Discussion}

In order to further research the influence of the microstructure properties of the SCSGP on the correlation between each independent influence factor and the macroscopic / microstructure characteristics. In this study, based on macroscopic / microstructure analysis, the SCSGPs were divided into workability, 
porosity, MIP and SEM results. And establish the relationship between each macroscopic / microstructure analysis and the 28 - days compressive strength, and drew a regression curve for comparison. First, the differences mechanical parameters (i.e., workability and porosity) of SCSGPs were discussed. Then through the MIP and SEM analysis to determine the relationship between the mechanical properties and microstructure characteristics of SCSGPs.

\subsection{Workability}

Panizza et al. indicated that the workability and compressive strength can be reasonably described by a power function [32]. Fig. 3 compared the correlation between compressive strength and workability at curing times of 1 and 28 days. Workability were $90-645 \mathrm{~min}$, and when the curing time of 1 day and 28 days, the compressive strength were $2.33-51.17 \mathrm{MPa}$ and $3.52-66.08 \mathrm{MPa}$, respectively. The results showed that the relationship between workability and compressive strength was nonlinear. It can be seen from Fig. 3(a) that when the SCS replacement levels increased from $0 \%$ to $40 \%$, the $r^{2}$ value of the regression equation was increased from 0.14 to 0.87 , and the correlation between its workability and compressive strength gradually increases. It shows that as the amount of SCS replacement levels increases, the impact of compressive strength was increases on workability. And under the same compressive strength, the setting time of the SCSGP increased with the amount of SCS replacement levels increased. In addition, when the curing times of 28 days and the SCS replacement levels of $40 \%$, the $r^{2}$ value was reduced to 0.81 , as shown in Fig. $3(\mathrm{~b})$. It is mainly due to the presence of too much SCS content, which reduced the solubility and hindered the geopolymerization. The unreacted particles of MK and SCS may exist in the structure of the SCSGP, and structural defect factors that affect the final mechanical properties [33]. Therefore, the correlation between the workability and the compressive strength of the SCSGP was gradually decreases. The relationship between the workability and compressive strength was conformed to the power function regression equation (2), where y was the final setting time $(\mathrm{min}), x$ was the compressive strength ( $\mathrm{MPa})$; $a$ and $b$ were two regression coefficients.

$$
y=a x^{b}
$$

According to the equation (2), the power function regression analysis results between workability and compressive strength were summarized in Table 7. When the curing time of 1 day, the results showed that it can be observed the coefficient b of the SCS replacement levels of $20 \%$ was the highest, indicating the compressive strength has the greatest impact on workability. Due to the synergistic effect between MK and SCS, the coefficient $b$ of the power function regression analysis result of the SCS replacement levels of $20 \%$ was the most influential; when the curing time was increased to 28 days, which can be observed that the coefficient b of the SCS replacement levels of $30 \%$ to $40 \%$ were the highest. Because the more SCS content will reduce the solubility, the unreacted particles of MK and SCS may exist in the structure of the SCSGP, and hindering the synergistic effect between MK and SCS [34], leading to structural defects, which in turn affects the final mechanical strength [33]. 


\subsection{Porosity}

Fig. 4 compares the correlation between the porosity and compressive strength. When the curing time of 1 day, the porosity of SCSGPs were 48.93-69.47\%, and the compressive strength of SCSGPs were 2.33$51.17 \mathrm{MPa}$; when the curing time of 28 days, the porosity of SCSGPs were $45.58-67.55 \%$, and the compressive strength of SCSGPs were 3.52-66.08 MPa. Fig. 4(a) showed that the porosity and compressive strength had a negative correlation. Keke et al. research showed that geopolymers had the lower porosity and denser structure, and the results of the pore structure was consistent with the change in the compressive strength [35]. At the same compressive strength, when the SCS replacement levels increased from $0 \%$ to $20 \%$, the $r^{2}$ value of the regression equation increases from 0.75 to 0.83 , and the linear regression had a trend of high accuracy. According to Asrani et al., which indicated that the linear regression has a high correlation accuracy and a good correlation [36], so that the compressive strength has a good correlation with the porosity. When the curing time of 28 days and the SCS replacement levels of $40 \%$, the $r^{2}$ value of the regression equation increased from 0.66 to 0.73 , which showed that the correlation increased with the curing time, as shown in Fig. 4(b). When the amount of SCS replacement levels exceeds $20 \%$, the SCS will quickly form oligomers and precipitate on the surface of the raw material particles, thereby hindering the content of MK and SCS dissolved during the equilibrium period, resulting in the reducing of the geopolymerization rate after the condensation point [34]. Therefore, when the SCS replacement levels of $40 \%$, the correlation of linear regression analysis between the porosity and the compressive strength was increased. The relationship between the porosity and compressive strength was conformed to the linear regression equation (3), where $y$ was the porosity (\%) and $x$ was the compressive strength (MPa); $a$ and $b$ were the two regression coefficients.

$$
y=a x+b
$$

According to the equation (3), the linear regression analysis results between porosity and compressive strength were summarized in Table 8. When the curing time of 1 day and the SCS replacement levels of $30 \%$, which showed that the coefficient was the highest (-0.33), indicating that the compressive strength has the greatest impact on porosity [37]. When the coefficient value was higher, which indicated that the two parameters had a great influence on each other [32;38]. From the results of the above linear regression analysis, it can be known that the synergy effect of MK and SCS has an influence interval of $20 \%$ SCS replacement levels. When the curing time was increased to 28 days, which observed that the coefficient a of the SCS replacement levels of $30 \%$ was increased to -0.26 . Due to the curing time increases to 28 days, which showed that its excessive SCS content will have a negative impact on the strength, result in the porosity increasing, and the linear regression analysis coefficient of a will increased. The research results were consistent with the Zhang et al. research [33].

\subsection{MIP analysis}


The pore distribution of five types SCSGPs (mixtures No. 26 - 30) were shown in Fig. 5. It can be seen from the figure, which showed that the large pores gradually move to the small pores with the curing time increased, and the pore distribution was changed by the reaction products gradually filling the large pores [39]. When the curing time of 28 days, it can be seen that the pores were mainly distributed at 10-20 nm, as shown in Fig. 5(b). Fig. 6 compares the correlation between the Si / Al ratio and the pore volume. The results showed that the $\mathrm{Si} / \mathrm{Al}$ ratio and the pore volume were a positive correlation. Hu et al. research showed that the high Si / Al molar ratio was promoted the dissolution and polycondensation of aluminosilicate [34]. When the curing of 1 day and the SCS replacement levels increases from $0 \%$ to $10 \%$, the $r^{2}$ value of the regression equation increases from 0.40 to 0.70 , this is due to the synergistic effect between MK and SCS, which makes the high degree of reaction of geopolymerization, forms more reaction products, and increasing the pore volume. When the curing age of 28 days and the SCS replacement levels of $40 \%$, the regression equation of $r^{2}=0.53$ was the lowest, but when the Si / Al molar ratio was too high ( $>2.5$ ), which will lead to decrease the degree of reaction and reaction products.

Therefore, the results of this study were consistent with those researches of Fernandez-Jimenez et al. and He et al. [40,41]. The relationship between the porosity and Si / Al molar ratio was conformed to the linear regression equation (3), where y was the porosity (\%) and x was the Si / Al molar ratio; a and b were the two regression coefficients.

According to the equation (4), the linear regression analysis results between porosity and Si / Al molar ratio were summarized in Table 9. The results showed that when the curing time of 1 day, which can be observed that the SCS replacement levels increases from $10 \%$ to $20 \%$, the coefficient was decreases from 28.98 to 13.67 , indicating that the effect of Si / Al ratio on the pore volume gradually decreases. When the SCS replacement levels of $40 \%$ and the curing time of 28 days, which observed the coefficient was decreased to 3.62. Due to the influence of excessive SCS, which caused the reaction rate of SCSGP decreased [33]. Therefore, when the Si / Al was relatively high, the coefficient of a decreased with the influence of the parameters. The results of this study were consistent with He et al. research [41].

\subsection{Microstructure analysis}

The SEM images of three types of SCSGPs (mixtures No. 26, 27, and 30) were shown in Fig. 7 and Fig. 8. When the curing time of 1 day and the SCS replacement levels of $0 \%$, the figure showed that the uniform plate particles was dispersed in the microstructure, which may be unreacted metakaolin (Fig. 7 (a)). According to Kljajević et al. research, the alkaline solution was the alkali activates the surface particles of metakaolin, which caused to dissolve and release $\mathrm{Si}^{4+}$ and $\mathrm{Al}^{3+}$ ions. Subsequently, the ions were participated in the geopolymerization reaction, resulting in the formation and growth of geopolymer gels [42]. Therefore, it can be clearly seen that the appearance of geopolymer gels and some unreacted metakaolin particles exist in the structure; when the curing age of 28 days, the $\mathrm{N}-\mathrm{A}-\mathrm{S}-\mathrm{H}$ gels were gradually filling the pores between the geopolymers, which showed that the structure of the mixture No. 26 was relatively dense, and the compressive strength tends to increase. At the early curing time (1 day) and SCS replacement levels of 10\%, the microstructure of the bonding area and the interface of SCSGP 
were denser (Fig. 7 (b)). Sun et al. indicated that the interface strength between binders were high, and it helps to increase the strength [43]. At the later curing age (28 days), it was observed that the mixture No. 27 sample was mainly filled with amorphous gel products (such as $\mathrm{N}-\mathrm{A}-\mathrm{S}-\mathrm{H}$ gels), resulting in a uniform and dense appearance of structure.

Fig. 7 (c) and Fig. 8 (c) were the SEM microstructure of the mixture No. 30 samples at different curing times of 1 to 28 days. When the curing age of 1 day and the SCS replacement levels of $40 \%$, the figure showed that the microstructure of pores and uniform plate particles were increased. Although, the MK and SCS had a synergistic effect, but the considerable amount of MK and SCS were still presented in the form of uniform plate particles (Fig. 7 (c)), and as structural defects exist in the geopolymer network structure, forming more macroporous structure. According to the observation results, when the curing age of 28 days, which observed that the strength of sample was reduced. Due to excessive SCS content, which will hinder the synergistic effect between MK and SCS [34], causing the aluminosilicate to precipitate and cover the surface of MK and SCS particles, thereby reducing the dissolution reaction activity, forming a loose structure with large pores and reducing its compressive strength development.

\section{Conclusion}

In this study, the DOE method was used to analyze the factors that affect the mechanical properties of SCSGPs through experiments and related statistical analysis. Without affecting the analysis results, the DOE method effectively reduces the number of samples, cost and experimental time. The main factors explaining the mechanical properties of SCSGPs and the related interaction effects were explained in detail. Multivariate statistical analysis was employed, and the relationship between the mechanical properties of the SCSGP and the interrelated parameters was predicted with an $\mathrm{r}^{2}$ value of greater than 0.869 after adjusting for the multivariate test coefficient.

The results of statistical analysis showed that the mainly factors of the compressive strength of the SCSGPs were had interactions between the NSR and DRA and between the NAR and DRA. NSR and NAR were the most significant factors, followed by DRA, the following regression equation had highly representative. Workability and compressive strength analysis results showed that when the SCS replacement levels of $20 \%$, the coefficient of b of the power function regression analysis result was the most influential, because the synergistic effect between MK and SCS. The porosity and compressive strength had a negative correlation. At the same compressive strength, when the SCS replacement levels increased from $0-20 \%$, the $r^{2}$ value of the regression equation increases from 0.75 to 0.83 , and the linear regression had a trend of high accuracy. The results of $\mathrm{Si} / \mathrm{Al}$ ratio and pore volume analysis showed that when the SCS replacement levels increase from 10-20\%, the coefficient was decreases from 28.98 to 13.67 , indicating that the effect of $\mathrm{Si} / \mathrm{Al}$ ratio on the pore volume gradually decreases. When the SCS replacement levels of $40 \%$ and the curing time of 28 days, which observed the coefficient was decreased to 3.62. Due to the influence of excessive SCS, which caused the reaction rate of SCSGP decreased. At the later curing age (28 days), the SEM observation was displayed that the mixture No. 27 sample was mainly filled with amorphous gel products (such as $\mathrm{N}-\mathrm{A}-\mathrm{S}-\mathrm{H}$ gels), resulting in a uniform and dense 
appearance of structure. In this study, the multivariate adaptive regression splines model provided a valid reference for the application of and future improvements in SCSGPS.

\section{Declarations}

\section{Availability of data and materials}

All data generated or analyzed during this study are available from the corresponding author upon request.

\section{Competing interests}

The authors declare they have no competing interests.

\section{Funding}

This work was supported by Ministry of Science and Technology of the Republic of China, Taiwan, for supporting this research financially (Contract No. MOST-109-2221-E-197-012-MY3).

\section{Authors' contributions}

Kang-Wei Lo: Writing - original draft. Methodology. Conceptualization. Ta-Wui Cheng: Supervision. YaWen Lin: Validation. Kae-Long Lin: Resources, writing-commenting and editing. All authors reviewed and approved the final manuscript.

\section{Acknowledgements}

The authors thank the Ministry of Science and Technology of the Republic of China, Taiwan, for supporting this research financially (Contract No. MOST-109-2221-E-197-012-MY3).

\section{References}

1. Yoko A, Oshima YS. Recovery of silicon from silicon sludge using supercritical water. J Supercrit Fluid. 2013;75:1-5.

2. Lo KW, Lin KL; Cheng TW, Zhang BX. The influence of sapphire substrate silicon carbide sludge on structural properties of metakaolin-based geopolymers. Environ Prog Sustain Energy. 2019;39:13305.

3. Tsai TH. Silicon sawing waste treatment by electrophoresis and gravitational settling. J Hazard Mater. 2011;189:526-530.

4. Lan A, Liu CE, Yan HL, Yua HT, Li IT, Hsua et al. Silicon ingot casting using reusable silicon nitride crucibles made from diamond wire sawing kerf-loss silicon. J Cryst Growth. 2019;525:125184.

5. Davidovits J. Geopolymer Chemistry and Applications. 2nd ed. Geopolymer Institute, Saint-Quentin, France; 
6. Si RZ, Guo SC, Dai QL, Wang JQ. Atomic-structure, microstructure and mechanical properties of glass powder modified metakaolin-based geopolymer. Constr Build Mater. 2020;254:119303.

7. Wan Q, Zhang YM, Zhang RB. Using mechanical activation of quartz to enhance the compressive strength of metakaolin based geopolymers. Cem Concr Compos. 2020;111:103635.

8. Nguyen TT, Bui HH, Ngo TD, Nguyen GD, Kreher MU, Darve FA. micromechanical investigation for the effects of pore size and its distribution on geopolymer foam concrete under uniaxial compression. Eng Fract Mech. 2019;209:228-244.

9. Łach M, Korniejenko KG, Mikuła J. Thermal insulation and thermally resistant materials made of geopolymer foams. Procedia Eng. 2016;151:410-416.

10. Sakkas K, Sofianos A, Nomikos P, Panias D. Behaviour of Passive Fire Protection K-Geopolymer under Successive Severe Fire Incidents. Materials. 2015;8:6096-6104.

11. Assaedi H, Alomayri T, Kaze CR, Jindal BB, Subaer S, Shaikh F, Alraddadi S. Characterization and properties of geopolymer nanocomposites with different contents of nano- $\mathrm{CaCO}_{3}$. Constr Build Mater. 2020;252:

12. Mesgari S, Akbarnezhad A, Xiao JZ. Recycled geopolymer aggregates as coarse aggregates for Portland cement concrete and geopolymer concrete: Effects on mechanical properties. Constr Build Mater. 2020;236:117571.

13. Top S, Vapur H, Altiner M, Kaya D, Ekicibil A. Properties of fly ash-based lightweight geopolymer concrete prepared using pumice and expanded perlite as aggregates. J Mol Struct. 2020;1202:127236.

14. Chougan M, Ghaffar SH, Jahanzat M, Albar A, Mujaddedi N, Swash R. The influence of nanoadditives in strengthening mechanical performance of 3D printed multi-binder geopolymer composites. Constr Build Mater. 2020;250:118928.

15. Askarian M, Tao Z, Samali B, Adam G, Shuaibu R. Mix composition and characterisation of one-part geopolymers with different activators. Constr Build Mater. 2019;225:526-537.

16. Zhang M, El-Korchi T, Zhang G, Liang J, Tao M. Synthesis factors affecting mechanical properties, microstructure, and chemical composition of red mud-fly ash based geopolymers. Fuel 2014;134:315-325.

17. Reddy MS, Dinakar P, Rao BH. A review of the influence of source material's oxide composition on the compressive strength of geopolymer concrete. Microporous Mesoporous Mater. 2016;234:12-23.

18. Diaz-Loya El, Allouche EN, Vaidya S. Mechanical properties of fly-ash-based geopolymer concrete. ACl Mater. J. 2011;108:300-306.

19. Rattanasak U, Chindaprasirt P. Influence of $\mathrm{NaOH}$ solution on the synthesis of fly ash geopolymer. Miner. Eng. 2009;22:1073-1078.

20. Mustafa AM, Al Bakri Abdullah MM, Kamarudin H, Binhussain M. The processing, characterization, and properties of fly ash based geopolymer concrete. Rev. Adv. Mater. Sci 2012;30:90-97. 
21. Songpiriyakij S, Kubprasit T, Jaturapitakkul C. Compressive strength and degree of reaction of biomass and fly ash-based geopolymer. Constr Build Mater 2010;24:236-240.

22. Adam AA. Strength and durability properties of alkali activated slag and fly ash-based geopolymer concrete. In: School of Civil, Environmental and Chemical Engineering, RMIT University, Melbourne, Australia. 2009. https://core.ac.uk/download/pdf/15614596.pdf. Accessed 15 May 2021.

23. Sumajouw DMJ, Hardjito D, Wallah SE, Rangan BV. Fly ash-based geopolymer concrete: study of slender reinforced columns. J Mater Sci. 2007;42:3124-3130.

24. Provis JL, van Deventer JSJ. Geopolymerisation kinetics. 1. In situ energy dispersive X-ray diffractometry. Chem Eng Sci. 2007;62:2309-2317.

25. Varanda C, Portugal I, Ribeiro J, Silva AMS, Silva CM. Optimization of bitumen formulations using mixture design of experiments (MDOE). Constr Build Mater. 2017;156:611-620.

26. Ohno M, Li VC. An integrated design method of Engineered Geopolymer Composite. Compos. 2018;88:73-85.

27. Lo KW, Lin KL, Cheng TW, Shiu HS. Effect of alkali activation thin film transistor-liquid crystal display waste glass on the mechanical behavior of geopolymers. Constr Build Mater. 2018;162:724-731.

28. Lan A, Liu CE, Yan HL, Yua HT, Li IT, Hsua HP, Lan CW. Silicon ingot casting using reusable silicon nitride crucibles made from diamond wire sawing kerf-loss silicon. J. Cryst. Growth. 2019;525:125184.

29. Wan Q, Rao F, Song S. Reexamining calcination of kaolinite for the synthesis of metakaolin geopolymers - roles of dehydroxylation and recrystallization. J Non Cryst Solids. 2017;460:74-80.

30. Chen H, Zhang YJ, He PY, Li CJ, Liu LC. Novel activated carbon route to low-cost geopolymer based porous composite with high mechanical resistance and enhanced $\mathrm{CO}_{2}$ Microporous Mesoporous Mater. 2020;305:110282.

31. Alvi MAA, Khalifeh M, Agonafir MB. Effect of nanoparticles on properties of geopolymers designed for well cementing applications. J Pet Sci Eng. 2020;191:107128.

32. Panizza M, Natali M, Garbin E, Tamburini S, Secco M. Assessment of geopolymers with Construction and Demolition Waste (CDW) aggregates as a building material. Constr Build Mater. 2018;181:119133.

33. Zhang F, Zhang LY, Liu M, Mu CZ, Liang YN, Hu X. Role of alkali cation in compressive strength of metakaolin based geopolymers. Ceram Int. 2017;43:3811-3817.

34. Hu Y, Liang S, Yang JK, Chen Y, Ye N, Ke et al. Role of Fe species in geopolymer synthesized from alkali-thermal pretreated Fe-rich Bayer red mud. Constr Build Mater. 2019;200:398-407.

35. Keke S, Xiaoqin P, Shuping W, Lu Z. Design method for the mix proportion of geopolymer concrete based on the paste thickness of coated aggregate. J. Clean. Prod. 2019;232:508-517.

36. Asrani NP, Murali G, Parthiban K, Surya K, Prakash A, Rathika K. feasibility of enhancing the impact resistance of hybrid fibrous geopolymer composites: Experiments and modelling. Constr Build Mater. 2019;203:56-68. 
37. Li N, Shi CJ, Zhang ZH, Wang H, Liu YW. A review on mixture design methods for geopolymer concrete. Composites Part B. 2019;178:107490.

38. Rafeet A, Vinai R, Soutsos M, Sha W. Guidelines for mix proportioning of fly ash / GGBS based alkali activated concretes. Constr Build Mater. 2017;147:130-42.

39. Rovnaník P. Effect of curing temperature on the development of hard structure of metakaolin-based geopolymer. Constr Build Mater. 2010;24:1176-1183.

40. ernandez-Jimenez A, Palomo A. Composition and Microstructure of Alkali Activated Fly Ash Binder. Cem Concr Res. 2005;35:1984-1992.

41. He PG, Wang MR, Fu SA, Jia DC, Yan S, Yuan et al. Effects of Si/Al ratio on the structure and properties of metakaolin based geopolymer. Ceram Int 2016;42:14416-14422.

42. Kljajević LM, Nenadović SS, Nenadović MT, Bundaleski NK, Todorović BŽ, Pavlović et al. Structural and chemical properties of thermally treated geopolymer samples. Ceram Int. 2017;43:6700-6708.

43. Sun ZQ, Lin XC, Vollpracht A. Pervious concrete made of alkali activated slag and geopolymers. Constr Build Mater. 2018;189:797-803.

\section{Tables}

Table 1 Mix design of the thirty-five (35) SCS-based geopolymers synthesized in this study. 


\begin{tabular}{|c|c|c|c|c|}
\hline No. & $\mathrm{SiO}_{2} / \mathrm{Na}_{2} \mathrm{O}$ & $S / L$ & MK (\%) & SCS (\%) \\
\hline 1 & 0.8 & 1.0 & 100 & 0 \\
\hline 2 & 0.8 & 1.0 & 90 & 10 \\
\hline 3 & 0.8 & 1.0 & 80 & 20 \\
\hline 4 & 0.8 & 1.0 & 70 & 30 \\
\hline 5 & 0.8 & 1.0 & 60 & 40 \\
\hline 6 & 1.2 & 1.0 & 100 & 0 \\
\hline 7 & 1.2 & 1.0 & 90 & 10 \\
\hline 8 & 1.2 & 1.0 & 80 & 20 \\
\hline 9 & 1.2 & 1.0 & 70 & 30 \\
\hline 10 & 1.2 & 1.0 & 60 & 40 \\
\hline 11 & 1.6 & 0.4 & 100 & 0 \\
\hline 12 & 1.6 & 0.4 & 90 & 10 \\
\hline 13 & 1.6 & 0.4 & 80 & 20 \\
\hline 14 & 1.6 & 0.4 & 70 & 30 \\
\hline 15 & 1.6 & 0.4 & 60 & 40 \\
\hline 16 & 1.6 & 0.6 & 100 & 0 \\
\hline 17 & 1.6 & 0.6 & 90 & 10 \\
\hline 18 & 1.6 & 0.6 & 80 & 20 \\
\hline 19 & 1.6 & 0.6 & 70 & 30 \\
\hline 20 & 1.6 & 0.6 & 60 & 40 \\
\hline 21 & 1.6 & 0.8 & 100 & 0 \\
\hline 22 & 1.6 & 0.8 & 90 & 10 \\
\hline 23 & 1.6 & 0.8 & 80 & 20 \\
\hline 24 & 1.6 & 0.8 & 70 & 30 \\
\hline 25 & 1.6 & 0.8 & 60 & 40 \\
\hline 26 & 1.6 & 1.0 & 100 & 0 \\
\hline 27 & 1.6 & 1.0 & 90 & 10 \\
\hline 28 & 1.6 & 1.0 & 80 & 20 \\
\hline
\end{tabular}

Page 15/26 


\begin{tabular}{|lllll|}
29 & 1.6 & 1.0 & 70 & 30 \\
30 & 1.6 & 1.0 & 60 & 40 \\
31 & 2.0 & 1.0 & 100 & 0 \\
32 & 2.0 & 1.0 & 90 & 10 \\
33 & 2.0 & 1.0 & 80 & 20 \\
34 & 2.0 & 1.0 & 70 & 30 \\
35 & 2.0 & 1.0 & 60 & 40 \\
\hline
\end{tabular}

* S/L: Solid/Liquid; MK: Metakaolin; SCS: Silicon Carbide Sludge

Table 2 The composition of Materials.

\begin{tabular}{|llll|}
\hline Composition & SCS & Kaolinite & $\mathrm{MK}$ \\
\hline $\mathrm{SiO}_{2}(\%)$ & 75.40 & 53.70 & 51.80 \\
\hline $\mathrm{Al}_{2} \mathrm{O}_{3}(\%)$ & 0.80 & 37.88 & 43.00 \\
\hline $\mathrm{Fe}_{2} \mathrm{O}_{3}(\%)$ & 0.58 & 0.88 & 1.30 \\
\hline $\mathrm{CaO}(\%)$ & 0.09 & 0.20 & 0.25 \\
\hline $\mathrm{SO}_{3}(\%)$ & 0.06 & - & - \\
\hline $\mathrm{Na}_{2} \mathrm{O}(\%)$ & - & 0.04 & 0.04 \\
\hline $\mathrm{K}_{2} \mathrm{O}(\%)$ & 0.01 & 0.34 & 0.32 \\
\hline $\mathrm{SiC}(\%)$ & 23.00 & - & - \\
\hline
\end{tabular}

Table 3 Results of compressive strength tests 


\begin{tabular}{|c|c|c|}
\hline \multirow[t]{2}{*}{ No. } & \multicolumn{2}{|c|}{ Compressive Strength (MPa) } \\
\hline & Mean & SD \\
\hline 1 & 50.07 & 3.25 \\
\hline 2 & 47.16 & 5.13 \\
\hline 3 & 48.43 & 6.77 \\
\hline 4 & 37.47 & 1.60 \\
\hline 5 & 37.00 & 3.37 \\
\hline 6 & 57.67 & 7.57 \\
\hline 7 & 63.64 & 4.20 \\
\hline 8 & 63.05 & 9.81 \\
\hline 9 & 59.24 & 8.79 \\
\hline 10 & 54.47 & 3.36 \\
\hline 11 & 17.18 & 0.84 \\
\hline 12 & 12.23 & 1.09 \\
\hline 13 & 9.71 & 0.47 \\
\hline 14 & 7.28 & 0.62 \\
\hline 15 & 3.52 & 0.22 \\
\hline 16 & 43.08 & 9.02 \\
\hline 17 & 36.26 & 3.58 \\
\hline 18 & 28.43 & 4.83 \\
\hline 19 & 24.61 & 1.72 \\
\hline 20 & 15.53 & 1.72 \\
\hline 21 & 61.76 & 4.40 \\
\hline 22 & 59.18 & 5.50 \\
\hline 23 & 57.71 & 9.43 \\
\hline 24 & 51.00 & 2.81 \\
\hline 25 & 26.88 & 1.92 \\
\hline 26 & 64.37 & 7.71 \\
\hline 27 & 66.08 & 9.13 \\
\hline
\end{tabular}

Page 17/26 


\begin{tabular}{|lll|}
28 & 64.59 & 6.77 \\
\hline 29 & 60.34 & 8.86 \\
30 & 46.90 & 2.94 \\
31 & 61.51 & 3.61 \\
32 & 54.43 & 5.82 \\
33 & 31.09 & 5.11 \\
34 & 17.35 & 1.83 \\
35 & 14.05 & 3.05 \\
\hline
\end{tabular}

Table 4 Multiple regression analysis for Compressive Strength and raw materials of the geopolymer (r2=0.984).

\begin{tabular}{|lllll|}
\hline Factor & Coef. & SE Coef. & $\mathrm{t}(35)$ & P-level $(<0.05)$ \\
\hline (1) $\mathrm{MK}$ & 29.960 & 1.996 & 15.013 & 0.000 \\
\hline (2) SCS & -25.540 & 4.186 & -6.101 & 0.000 \\
\hline (3) $\mathrm{Na}$ SSiO3 & 39.785 & 5.180 & 7.681 & 0.000 \\
\hline (4) $\mathrm{NaOH}$ & -15.365 & 3.512 & -4.375 & 0.000 \\
\hline (1) by (2) & 55.500 & 4.537 & 12.233 & 0.000 \\
\hline (1) by (3) & -9.825 & 4.743 & -2.072 & 0.045 \\
\hline (1) by (4) & 45.325 & 3.336 & 13.588 & 0.000 \\
\hline (2) by (3) & -65.325 & 3.824 & -17.085 & 0.000 \\
\hline (2) by (4) & -10.175 & 2.624 & -3.878 & 0.000 \\
\hline (3) by (4) & 55.150 & 3.637 & 15.163 & 0.000 \\
\hline
\end{tabular}

Table 5 Results of multiple regression analysis for Compressive Strength and dimensionless ratio of the geopolymer $(\mathrm{r} 2=0.826)$. 


\begin{tabular}{|lllll|}
\hline Factor & Coef. & SE Coef. & $\mathrm{t}(35)$ & P-level $(<0.05)$ \\
\hline SN & -42.540 & 3.142 & -13.538 & 0.000 \\
\hline SL & -43.190 & 3.106 & -13.905 & 0.000 \\
\hline OW & -43.896 & 3.131 & -14.020 & 0.000 \\
\hline
\end{tabular}

*OW: $\mathrm{OH}^{-} /$Water

Table 6 Results of multiple regression analysis for Compressive Strength and molecular composite ion $(\mathrm{r} 2=0.869)$.

\begin{tabular}{|lllll|}
\hline Factor & Coef. & SE Coef. & $\mathrm{t}(35)$ & P-level $(<0.05)$ \\
\hline (1) NSR & -43.918 & 3.129 & -14.038 & 0.000 \\
\hline (2) NAR & -43.845 & 3.130 & -14.008 & 0.000 \\
\hline (3) DRS & -1.487 & 2.329 & -0.639 & 0.527 \\
\hline (4) DRA & 14.651 & 3.187 & 4.597 & 0.000 \\
\hline (5) $\mathrm{OH}^{-}(\mathrm{M})$ & -39.612 & 3.159 & -12.539 & 0.000 \\
\hline (1) by (2) & -0.073 & 0.011 & -6.779 & 0.000 \\
\hline (1) by (3) & -42.431 & 1.334 & -31.810 & 0.000 \\
\hline (1) by (4) & -58.569 & 0.147 & -398.537 & 0.000 \\
\hline (1) by (5) & -4.306 & 0.423 & -10.181 & 0.000 \\
\hline (2) by (3) & -42.358 & 1.333 & -31.786 & 0.000 \\
\hline (2) by (4) & -58.496 & 0.151 & -387.180 & 0.000 \\
\hline (2) by (5) & -4.233 & 0.427 & -9.906 & 0.000 \\
\hline (3) by (4) & -16.138 & 1.370 & -11.779 & 0.000 \\
\hline (3) by (5) & 38.125 & 1.280 & 29.786 & 0.000 \\
\hline (4) by (5) & 54.263 & 0.337 & 160.985 & 0.000 \\
\hline
\end{tabular}

Table 7 The power function regression analysis results between workability and compressive strength. 


\begin{tabular}{|llllll|}
\hline \multicolumn{2}{|c|}{ Curing Time= 1 day } & \multicolumn{5}{c|}{ Curing Time= 28 days } \\
\hline $\begin{array}{l}\text { SCS } \\
\text { (wt. \%) }\end{array}$ & a & b & SCS & a & b \\
\hline 0 & 385.16 & 0.25 & 0 & 347.33 & 0.21 \\
\hline 10 & 474.39 & 0.25 & 10 & 485.17 & 0.24 \\
\hline 20 & 1168.19 & 0.46 & 20 & 919.89 & 0.36 \\
\hline 30 & 948.73 & 0.39 & 30 & 1115.24 & 0.41 \\
\hline 40 & 919.18 & 0.36 & 40 & 1252.25 & 0.41 \\
\hline
\end{tabular}

Table 8 The linear regression analysis results between porosity and compressive strength.

\begin{tabular}{|llllll|}
\hline \multicolumn{2}{|l}{ Curing Time= 1 day } & \multicolumn{4}{l|}{ Curing Time= 28 days } \\
\hline SCS & a & b & SCS & a & b \\
(wt. \%) & & & (wt. \%) & & \\
\hline 0 & -0.41 & 70.79 & 0 & -0.27 & 64.65 \\
\hline 10 & -0.44 & 71.70 & 10 & -0.27 & 64.90 \\
20 & -0.35 & 68.17 & 20 & -0.27 & 65.15 \\
30 & -0.33 & 66.90 & 30 & -0.26 & 65.64 \\
\hline 40 & -0.39 & 68.40 & 40 & -0.35 & 67.95 \\
\hline
\end{tabular}

Table 9 The linear regression analysis results between porosity and Si/Al molar ratio. 


\begin{tabular}{|llllllll|}
\hline \multicolumn{4}{|c}{ Curing Time= 1 day } & \multicolumn{4}{c|}{ Curing Time= 28 days } \\
\hline SCS & $\mathrm{a}$ & $\mathrm{b}$ & $\mathrm{R}^{2}$ & $\mathrm{a}$ & $\mathrm{b}$ & $\mathrm{R}^{2}$ \\
(wt. \%) & & & & & & \\
\hline 0 & 4.42 & 90.27 & 0.40 & 4.72 & 92.26 & 0.92 \\
\hline 10 & 28.98 & 52.33 & 0.70 & 22.47 & 63.30 & 0.38 \\
\hline 20 & 13.67 & 74.72 & 0.11 & 9.44 & 81.66 & 0.10 \\
\hline 30 & 69.30 & -35.95 & 0.82 & 24.38 & 49.72 & 0.84 \\
\hline 40 & 15.15 & 41.01 & 0.10 & 3.62 & 82.47 & 0.53 \\
\hline
\end{tabular}

Figures

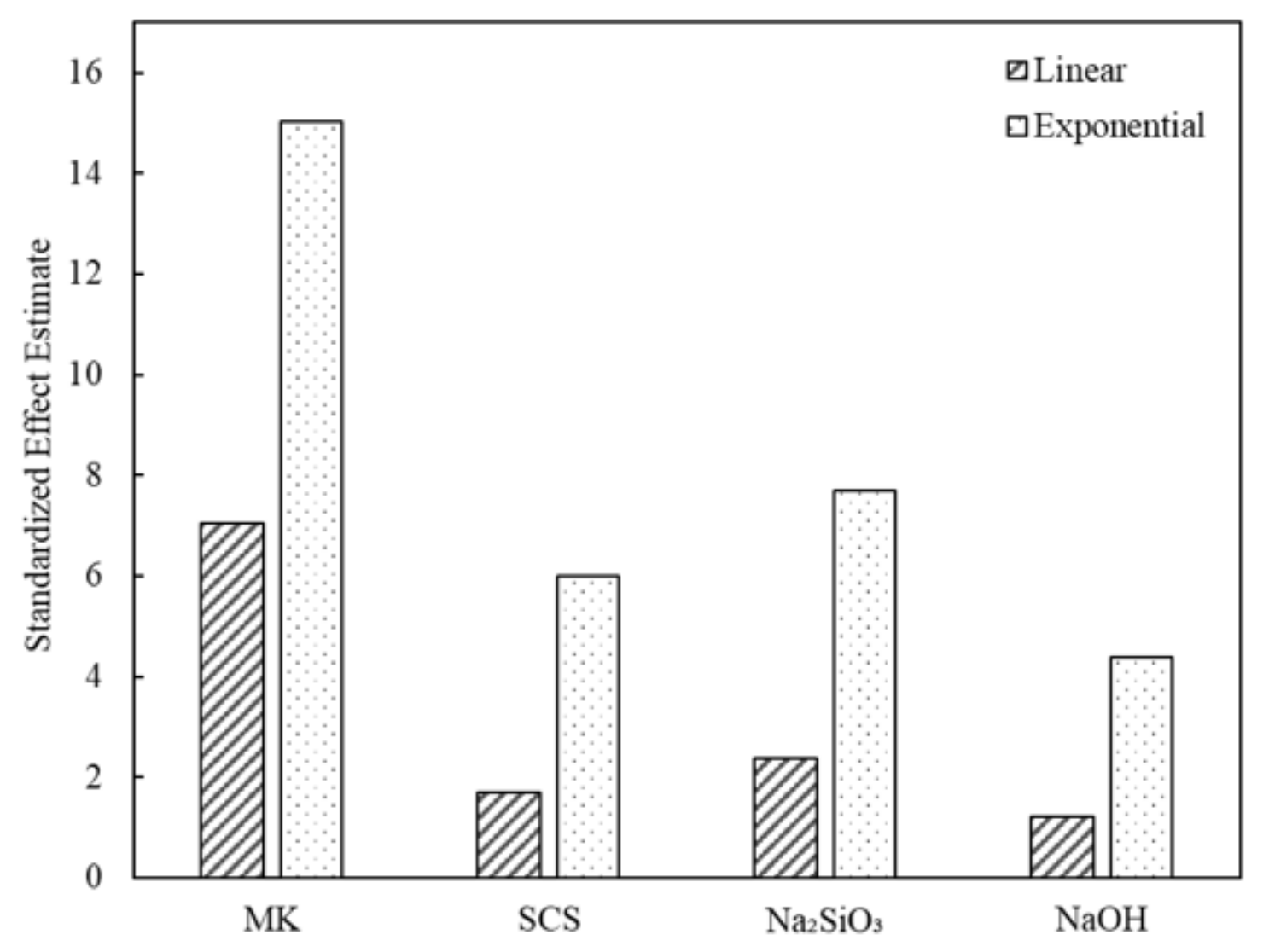

Figure 1

Statistical analysis results of standardized effects between Compressive Strength and raw materials of the geopolymer. 


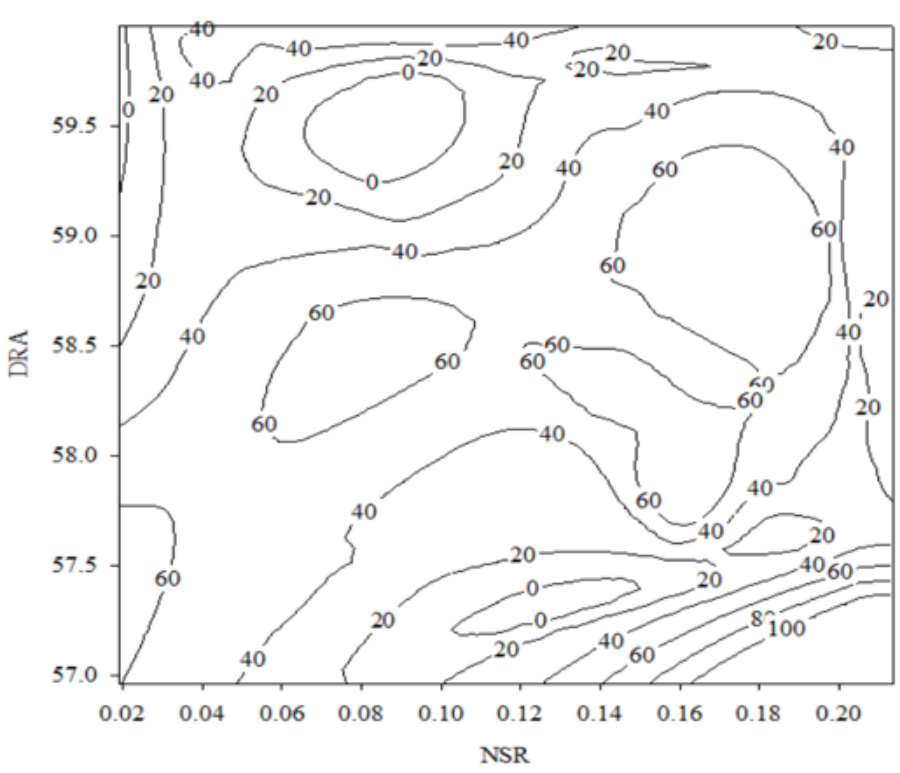

(a)

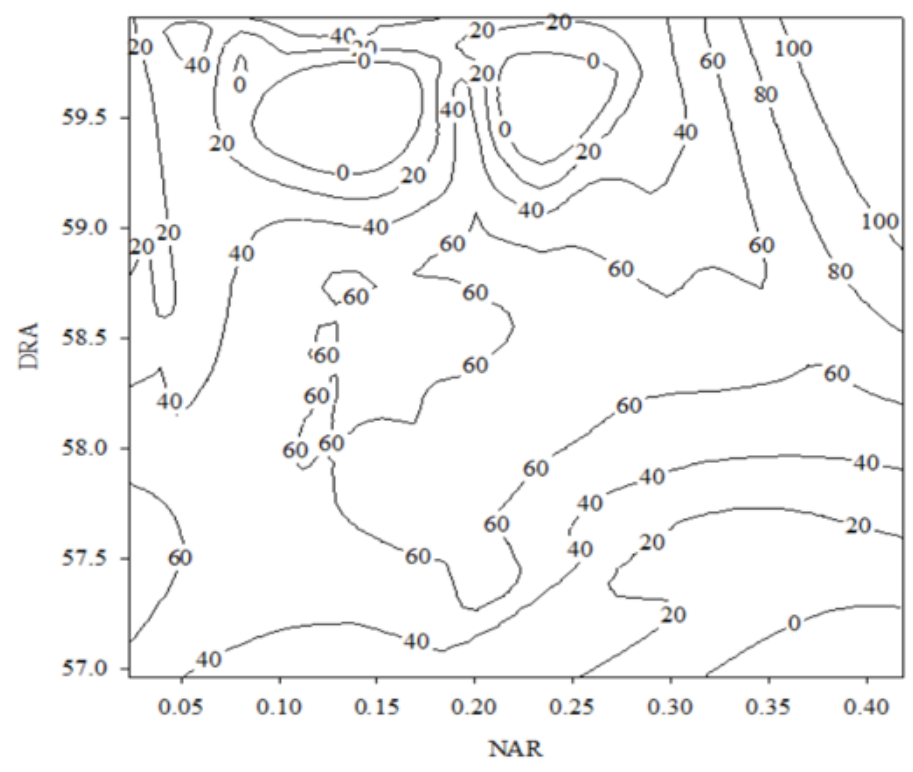

(b)

\section{Figure 2}

Relationship between Compressive Strength and the first three significantfactors of the SCS-based geopolymers, i.e. NSR, NAR, and DRA (\%).

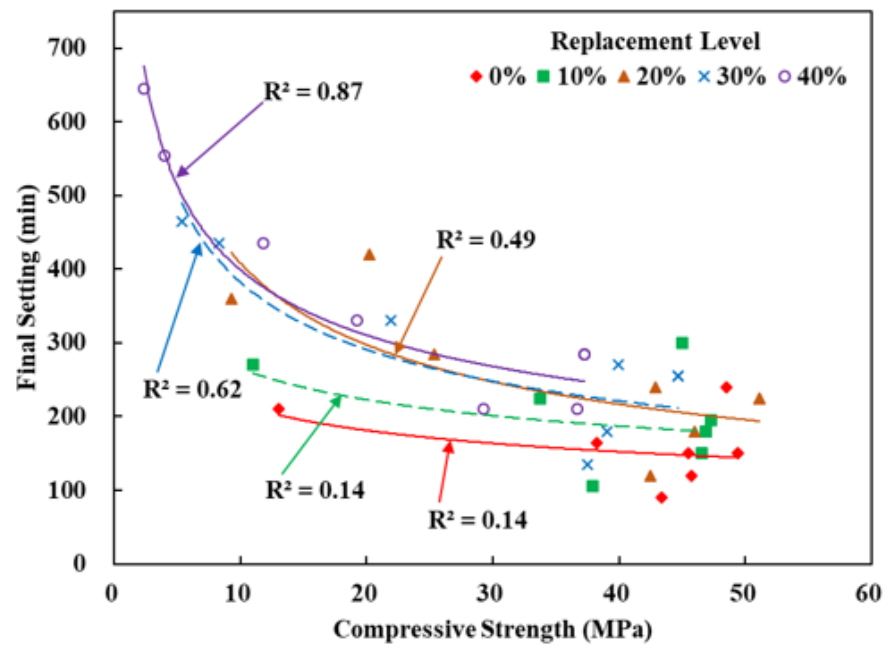

(a)

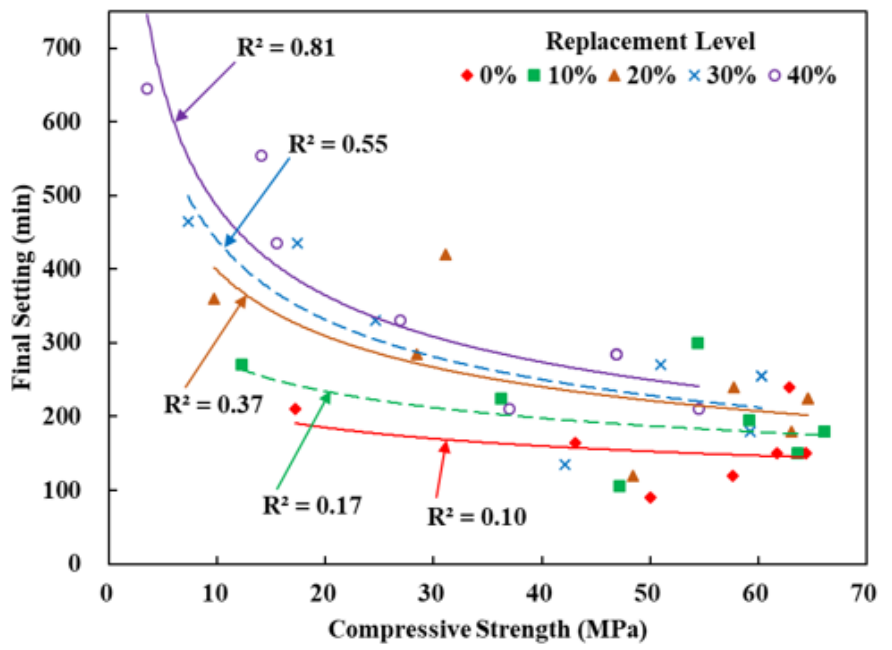

(b)

\section{Figure 3}

The power function regression analysis results between workability and compressive strength (a) 1 day $\mathbb{}$ (b) 28 days. 


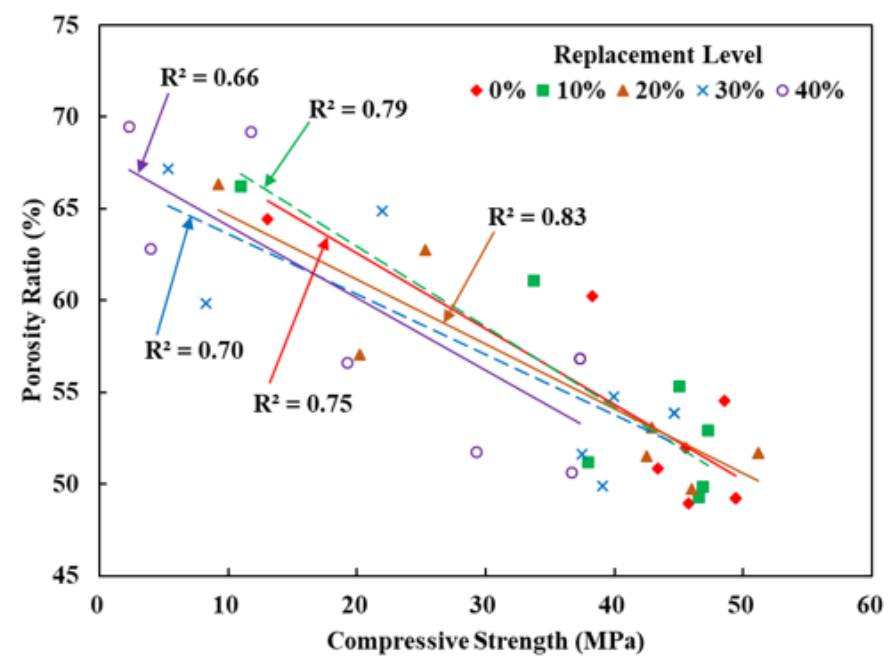

(a)

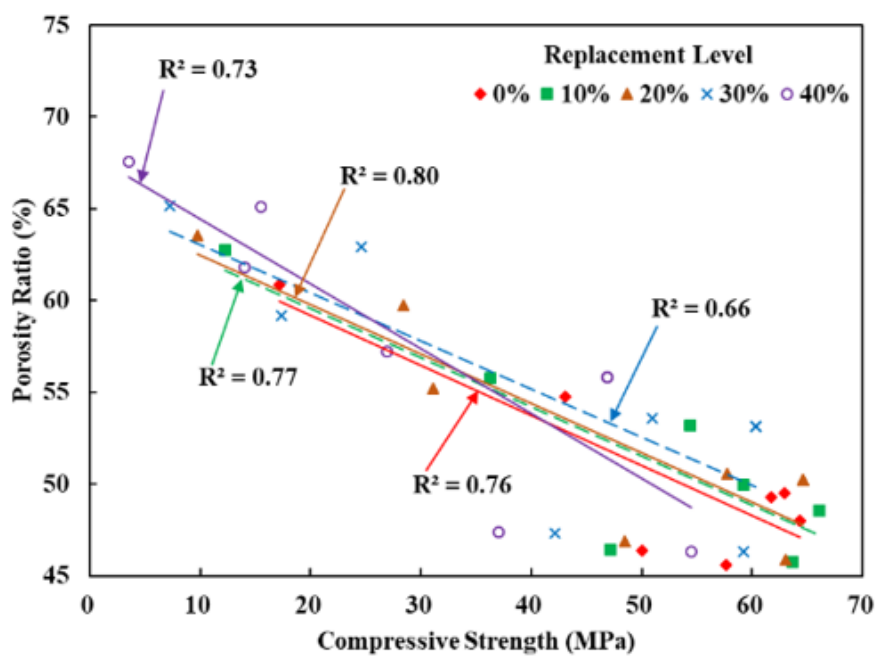

(b)

\section{Figure 4}

The linear regression analysis results between porosity and compressive strength (a) 1 day $\mathbb{( b )} 28$ days.

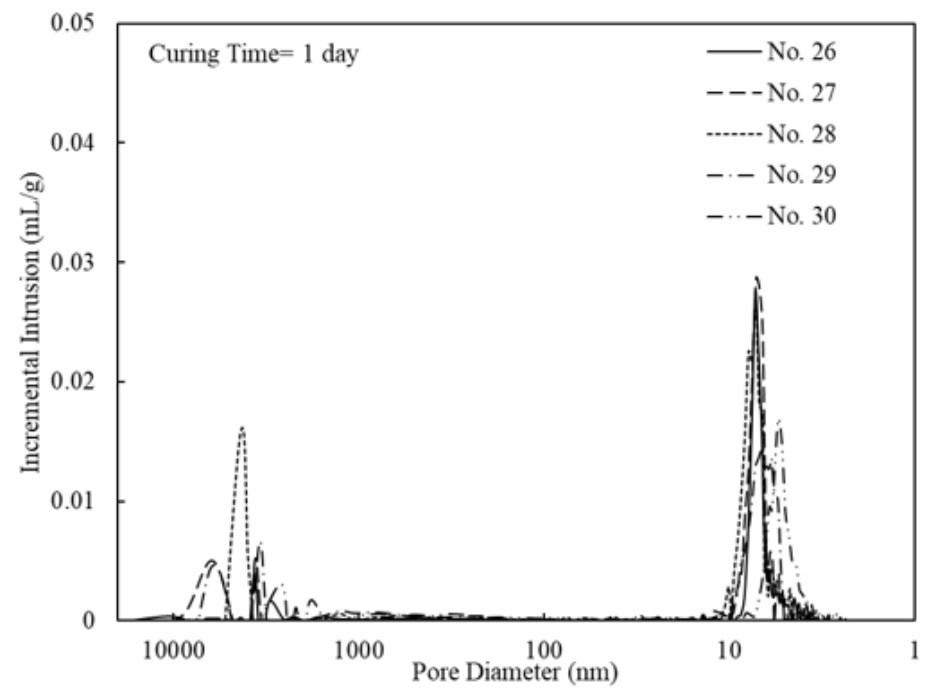

(a)

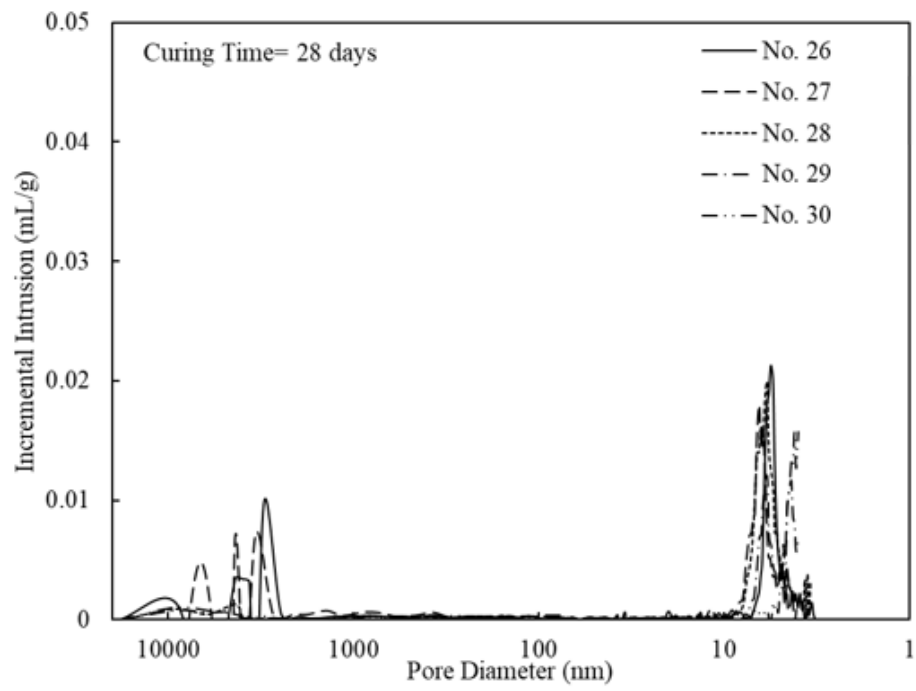

(b)

\section{Figure 5}

The pore distribution of five types SCSGPs (mixtures No. 26-30) (a) 1 day $\llbracket(b) 28$ days. 


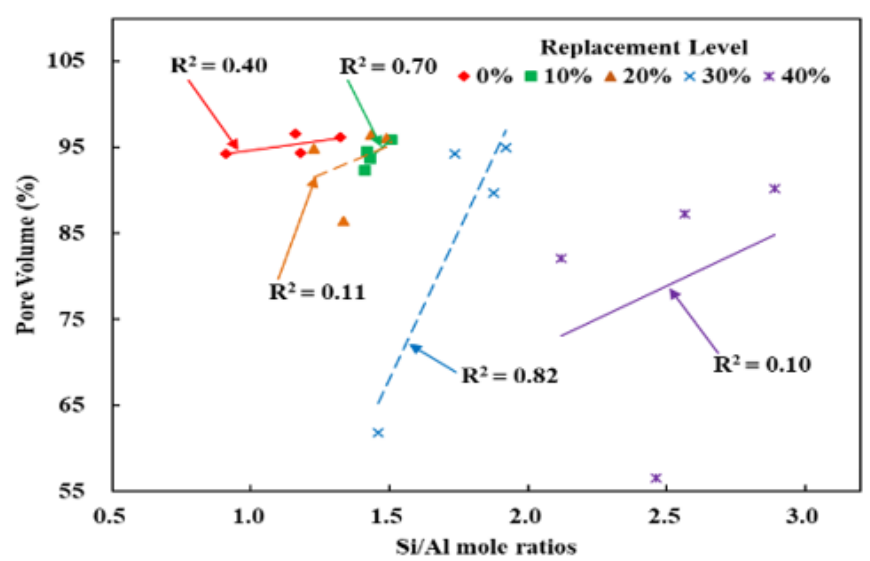

(a)

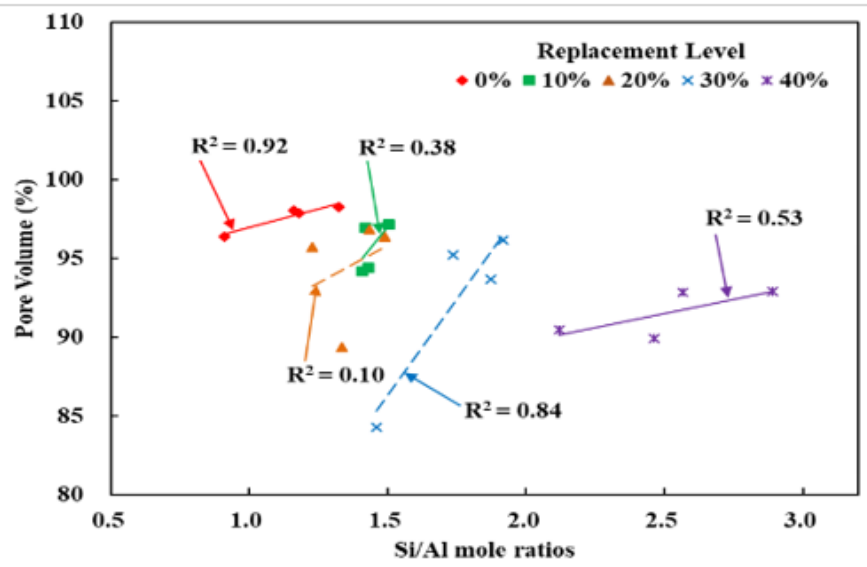

(b)

\section{Figure 6}

The linear regression analysis results between porosity and Si/AI molar ratio (a) 1 day $\mathbb{\text { (b) }} 28$ days. 


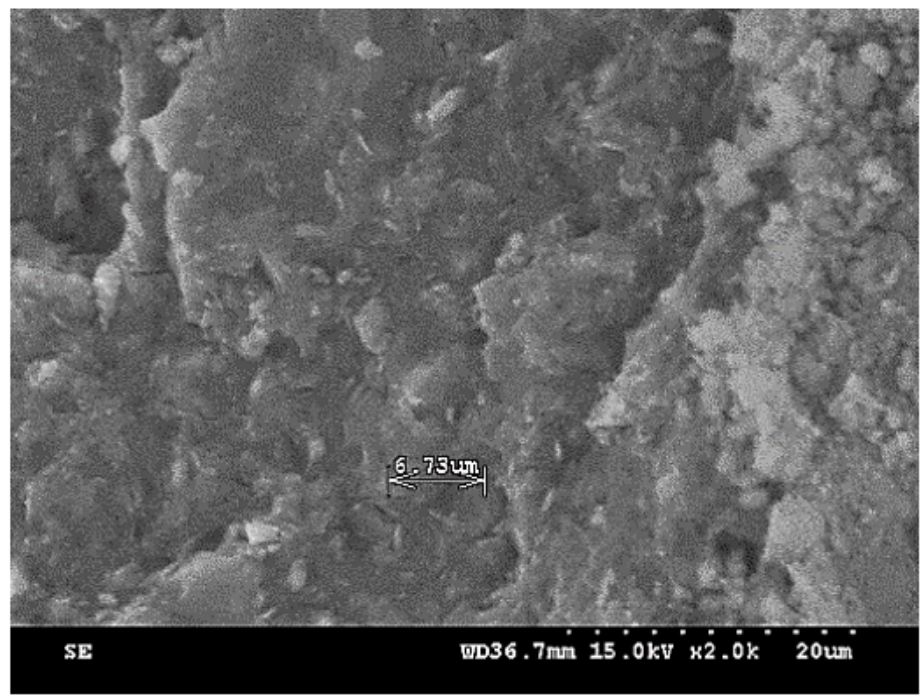

(a) No. 26

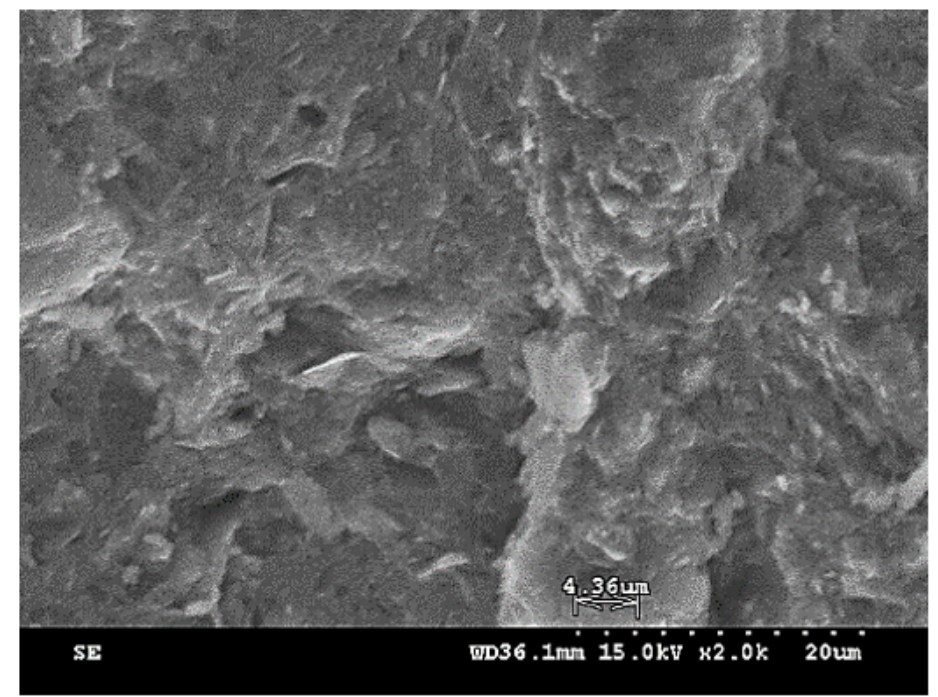

(b) No. 27

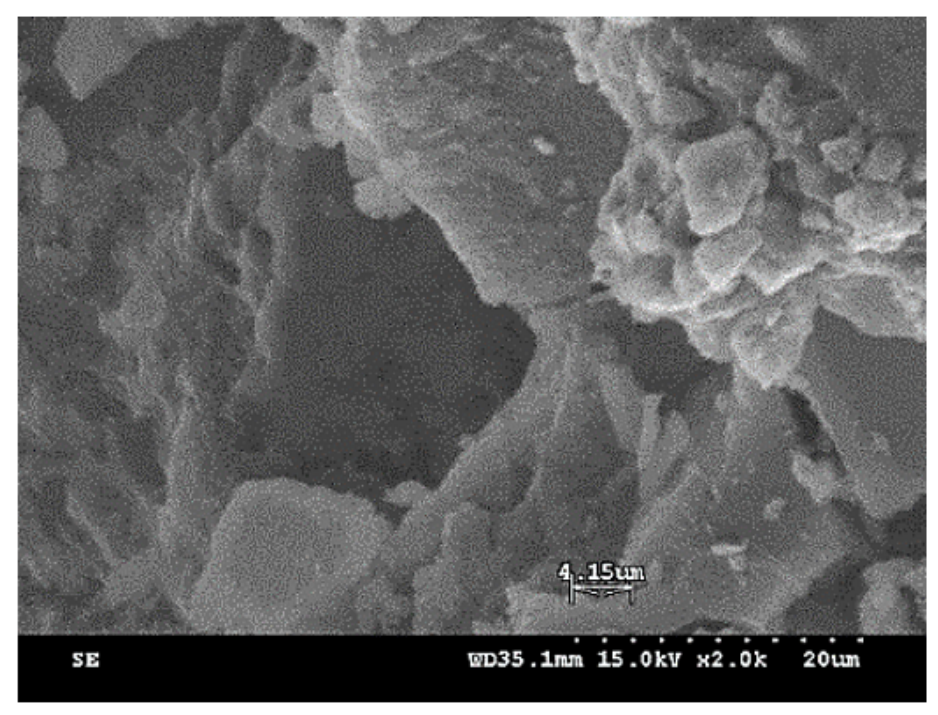

(c) No. 30

\section{Figure 7}

The SEM images of three types of SCSGPs (mixtures No. 26, 27, and 30) at the curing times of 1 day. 


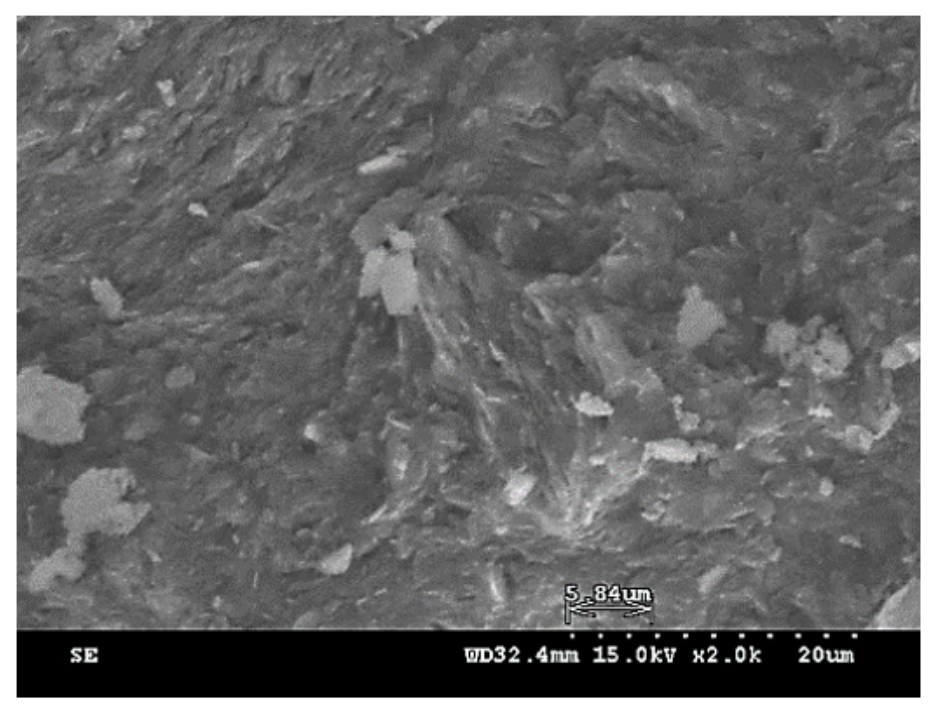

(a) No. 26

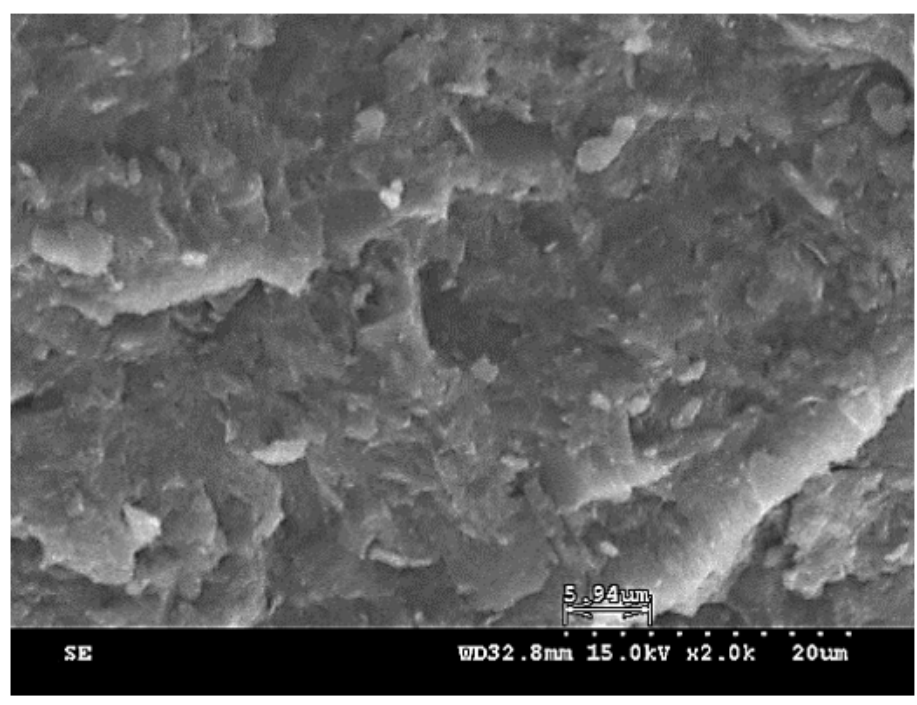

(b) No. 27

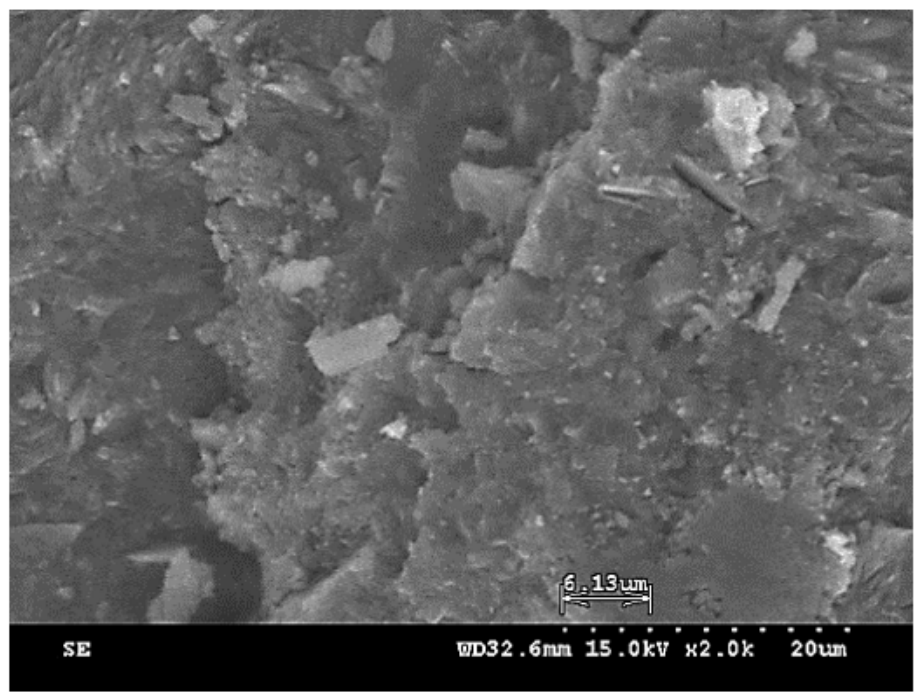

(c) No. 30

\section{Figure 8}

The SEM images of three types of SCSGPs (mixtures No. 26, 27, and 30) at the curing times of 28 days. 